\title{
CAPTIVE PROPAGATION OF THREATENED PRIMATES - THE EXAMPLE OF THE LION-TAILED MACAQUE MACACA SILENUS
}

\author{
Werner Kaumanns ${ }^{1}$, Mewa Singh ${ }^{2} \&$ Alexander Sliwa $^{3}$ \\ ${ }^{1}$ LTM Research and Conservation, Eschenweg 5, 37130 Gleichen, Germany \\ ${ }^{2}$ Biopsychology Laboratory, University of Mysore, Mysuru, Karnataka 570006, India \\ ${ }^{2}$ Organismal and Evolutionary Biology Unit, Jawaharlal Nehru Centre for Advanced Scientific Research, Jakkur, \\ Bengaluru, Karnataka 560064, India \\ ${ }^{3}$ Zoologischer Garten Köln, Riehler Straße 173, 50735 Köln, Germany \\ ${ }^{1}$ silenus@t-online.de, ${ }^{2}$ mewasinghltm@gmail.com (corresponding author), ${ }^{3}$ sliwa@koelnerzoo.de
}

OPEN ACCESS

\begin{abstract}
Many conservation-oriented breeding programs are not likely to reach their goal of establishing self-sustaining populations. Some zoo biologists propagate to reconsider zoo-based conservation policies and strategies. The Lion-tailed Macaque is a flagship species for in situ conservation and a high priority species in captive propagation. This article reviews the captive management history of the Liontailed Macaque, identifies management patterns that might have negatively influenced the development of the programs, and proposes to use this analysis to initiate a new management perspective. In the North American captive Lion-tailed Macaque population under the Species Survival Plan (SSP), the strong reduction in population size and group sizes due to space problems might have contributed to a decrease in population viability. The population over two decades has declined from almost 300 to less than 100 individuals. In the European population under the European Endangered Species Program (EEP), population size was not limited and larger groups were advocated. The population grew slowly but steadily to a present size of more than 350 individuals over about 23 years. The effective population size has remained low in both SSP and EEP populations. A general conceptual framework that focuses on individuals and their phenotypes for in situ and ex situ conservation recently developed by field conservationists is briefly introduced. It is used to suggest improvements in the management of the Lion-tailed Macaque. It is concluded that the size and structure of a breeding population is to be decided so as to provide conditions and materials for successful reproduction rather than by the available zoo space only. For this, large groups and populations with representation of all age-sex classes are advocated. This would result in a further reduction in the number of species kept in zoos. It is indicated that zoo biology needs to develop new concepts that include a large spectrum of concepts of biology and knowledge about the adaptive potential of animal species under altered and fragmented conditions.
\end{abstract}

Keywords: Behaviour, captive propagation, effective population size, European Endangered Species Program, individual-based management, Lion-tailed Macaque, primate conservation, Species Survival Plan.

DOI: http://dx.doi.org/10.11609/JoTT.03625.4825-39 | ZooBank: urn:Isid:zoobank.org:pub:7BB73AF7-0E44-48F3-9234-B8BA35054503

Editor: Karin Schwartz, George Mason University, Fairfax, Virginia.

Date of publication: 26 October 2013 (online \& print)

Manuscript details: Ms \# 03625 | Received 15 May 2013 | Final received 08 October 2013 | Finally accepted 09 October 2013

Citation: Kaumanns, W., M. Singh \& A. Sliwa (2013). Captive propagation of threatened primates - the example of the Lion-tailed Macaque Macaca silenus . Journal of Threatened Taxa 5(14): 4825-4839; http://dx.doi.org/10.11609/JoTT.03625.4825-39

Copyright: (C) Kaumanns et al. 2013. Creative Commons Attribution 3.0 Unported License. JoTT allows unrestricted use of this article in any medium, reproduction and distribution by providing adequate credit to the authors and the source of publication.

Funding: German Primate Centre (DPZ = Deutsches Primatenzentrum ) and of Cologne Zoo (Kölner Zoo) supported the work for the LTM European Breeding Program.

Competing Interest: Authors declare no competing interests.

Author Contribution: Equal contribution.

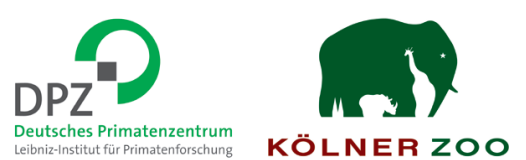

Author Details: WERNER KAUMANNS worked as a scientist and Head of Breeding and Husbandry section at DPZ for almost two decades then was a curator of primates at Cologne Zoo. He was the LTM EEP coordinator for the Lion-tailed Macque from 1989-2006 and worked with LTM both in situ and ex situ. He is specifically interested in the effects of altered living conditions on primates.

MEWA SINGH has been working on primates for three decades and has spent considerable time in the field studying the behaviour and the ecology of Lion-tailed Macaqes and of several other primate species.

ALEXANDER SLIWA is a curator of primates and of other mammals at Cologne Zoo. He is a member of the EAZA Old World Monkey Taxon Advisory Group. He is also working longterm with felid and hyaenid populations, both in situ and ex situ.

Acknowledgements: We thank Dr. Tom Ness and Dr. Scott Carter for providing SSP Studbook data, for helpful discussions and for supporting conservation-oriented research on the Lion-tailed Macaque in southern India. We also thank the reviewers for their very insightful comments; Tiergarten Wels, Austria, and Zoo Dresden, Germany, for supporting in situ conservation research in southern India; Prof. Dr. H.J. Kuhn, founding director at DPZ, for his initiative to work with Lion-tailed Macaques and to contribute to their conservation. 


\section{INTRODUCTION}

There is a growing number of studies that critically analyze the status of captive populations of wild animals in conservation-oriented breeding programs. It seems that many programs are not likely to reach their goal of establishing self-sustaining populations that can serve as a reserve for their threatened wild counterparts (Kaumanns et al. 2000; Lees \& Wilcken 2009; Conway 2011; Lacy 2013). Many breeding programs for primates are also facing these problems. Due to low breeding success, they do not grow properly and are at risk of losing genetic and phenotypic diversity, and a discussion of the possible reasons for the problem has been started (Kaumanns et al. 2000, 2008). The awareness among the international zoo community of the seriousness of the situation, however, seems to be still limited. Only a few zoo biologists propagate to reconsider or redefine the relevant zoo-based conservation policies and strategies. According to Conway (2011), a more sharply focussed approach and more support for, and collaboration with, parks and reserves are needed for "buying time for wild animals with zoos". Lacy (2013) discusses how to achieve "true sustainability" of zoo populations. This would require managing isolated zoo populations as part of a metapopulation both within a global species management program and together with small populations in the wild.

The Lion-tailed Macaque Macaca silenus is a flagship species for the many endemic and threatened animal and plant species of the Western Ghats, southern India, and a high priority species in captive propagation. It was one of the first primate species for which, in 1983 , a National (USA) and in 1987 an International Studbook was established (Gledhill 1987) and one of the first for which a Species Survival Plan (SSP) and a European Endangered Species Programme (EEP) were established in 1980 and 1989, respectively, in North America and Europe. A recent analysis of the conservation history of the Lion-tailed Macaque, however, concluded that even after more than three decades of both in situ and ex situ efforts, the status of both the wild and the global captive population has not significantly improved (Singh et al. 2009). This seems to be specifically the case for the global captive population, where the majority of the subpopulations did not develop satisfactorily despite a promising start.

The aim of this paper is to review the management history of the captive population of the Lion-tailed Macaque to identify management patterns that might have negatively influenced its development. This analysis will be used to promote the initiation of new management perspectives for the Lion-tailed Macaque as well as for other primate species.

\section{MATERIALS AND METHODS}

The material used in this analysis has been obtained from studbooks and reports of the EEP (1989-2012) and the SSP (1981-2012). In addition, author WK has a long experience of managing captive populations of Liontailed Macaques and other primate species and worked as the species coordinator for the Lion-tailed Macaque EEP between 1989 and 2006. Author MS has decades of experience studying Lion-tailed Macaques in their natural habitats in the Western Ghats. Author AS has been the EEP coordinator for the Lion-tailed Macaque since 2006 and the International Studbook keeper since 2013.

\section{STATUS \\ DEVELOPMENT OF THE HISTORICAL CAPTIVE POPULATION}

The global historical population covering a recording period of more than 100 years includes the present living population of about 500 individuals worldwide. A total captive population of 1,041 individuals with the first record going back to 1,899 was documented in the first International Studbook (Gledhill 1987) for the Lion-tailed Macaque. More recently, Ness (2011) recorded a total of 878 (426.385.67) individuals (North American Studbook) and Sliwa (2011; European Studbook) reported 1,150 (514.547.89) individuals. The global international studbook is not yet fully updated. A tentative estimation of the number of individuals kept in other regions would add another 500, thus leading to a total historical population of about 2,500 individuals. An estimated minimum of $30 \%$ of these were wild caught mainly in the first decades of the 20th century. As of the end of 2005 Lion-tailed Macaques were kept on all continents except Africa and Antartica, with the two largest subpopulations living in North America and Europe and smaller populations in India, Japan, China, Korea, Malaysia, Mexico, and Australia (Fitch-Snyder 2006). The development of the two largest sub-populations, which constitute the main parts of the global population, is described below.

\section{North America}

Figure 1 shows the development of the North American population for a period of 50 years between 1960 and 2008. After an increase to a peak of 268 


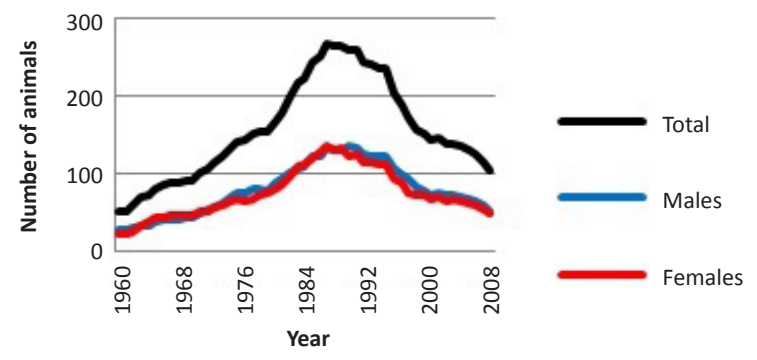

Figure 1. Development of the North American LTM population between 1960 and 2010 (see Ness 2011).

individuals in 1988 (Ness 2011), it steadily decreased to a size of 88 (44.44) individuals kept in 20 institutions in 2011. The most recent census in 2012 reveals a number of 74 (37.37.0) individuals (Ness, pers. comm. 2013).

According to the 2011 Studbook, from the 346 females recorded, 182 (52.6\%) were recorded dams. The lifetime mean number of births per dam is 4.05 , the median is 4 (only for recorded dams, not all females, and does not include offspring with unknown dams; $N=559$ births from 138 dams, $\max =13$, min=1).

At present, none of the 54 founder individuals is alive. The current managed population of 46 (20.26.0) has a genetic diversity of $96 \%$ but with an effective to actual population size ratio $\left(\mathrm{N}_{\mathrm{e}} / \mathrm{N}\right)$ of only 0.12 which is far below the typical ratio of 0.30 . This indicates a very low breeding potential of this population (Carter \& Ness 2012).
It is reported that there were large differences in reproductive output for the females and even more for the males (Lindburg et al. 1989; Lindburg \& Forney 1992; Lindburg 2001). No systematic information is available on the effects of birth control on productivity patterns on population level. Figure 2 shows the development of the North American population with reference to births, deaths, exports and imports. Since about 1990, there has been a considerable decrease in population size.

\section{Europe}

Figure 3 and Figure 4 show the development of the European population. The population slowly but steadily increased to a size of 343 individuals (145.180.18) in 2011, kept in 43 institutions (Sliwa 2011). The development with reference to births, deaths and imports has been reported by Kaumanns et al. (2006). In the 1960s and 1970s, population growth was mainly influenced by the import of wild-born Lion-tailed Macaques. Between 1985 and 1987, a further 39 individuals were imported from the SSP population. Kaumanns et al. (2006) and Sliwa (2011) show that the mean annual birth rate only slightly increased over the decades. Mean annual mortality rate, however, decreased considerably, whereas the mean annual infant mortality increased over the years to a level of $35 \%$, where it remained constant. The mean annual birth rate was only slightly higher than the mean annual mortality rate, thus leading to the slow population growth. Taking into account the varying number of adult

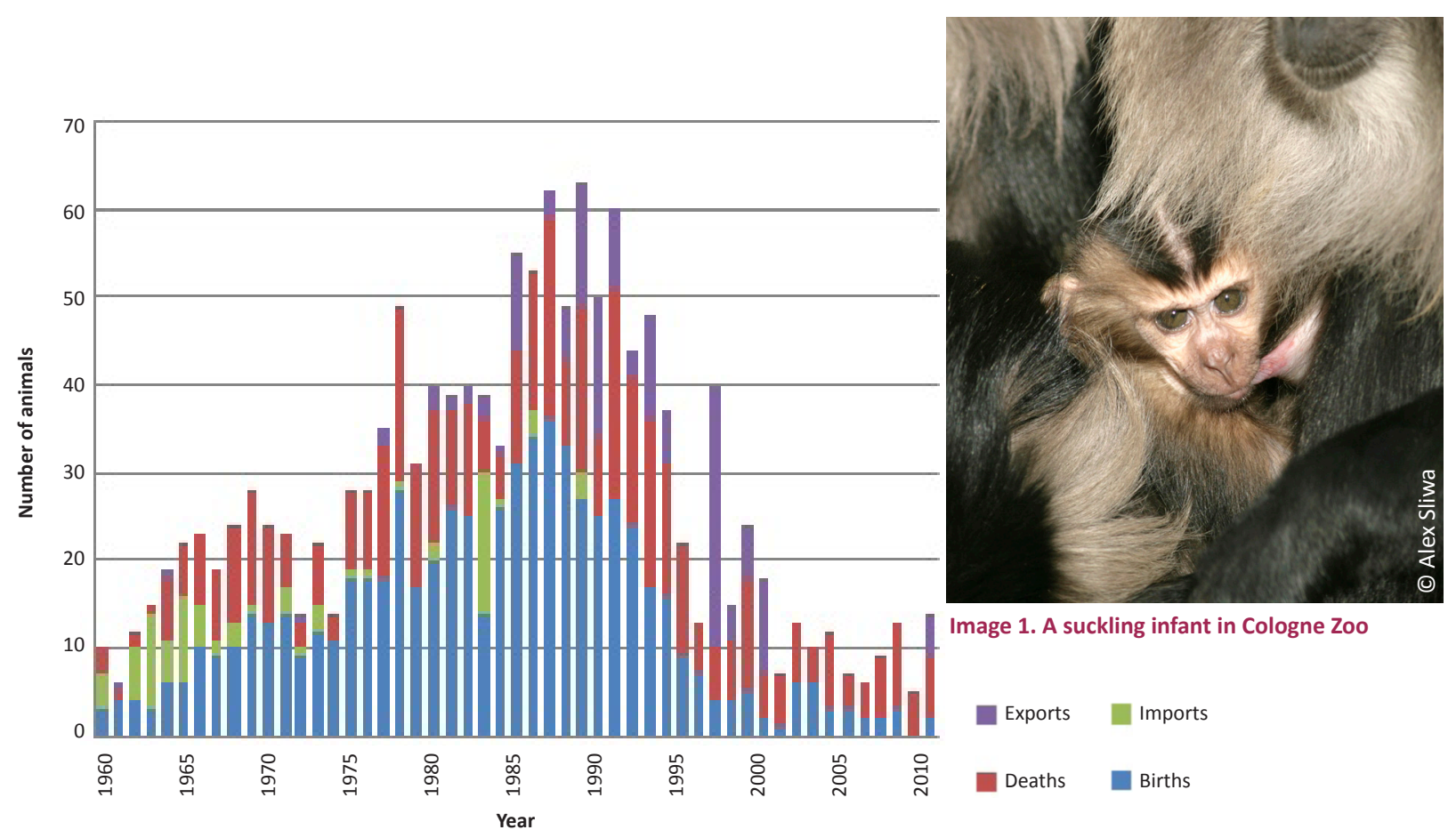

Figure 2. Development of the North American population with reference to births, deaths, exports and imports (see Ness 2011). 


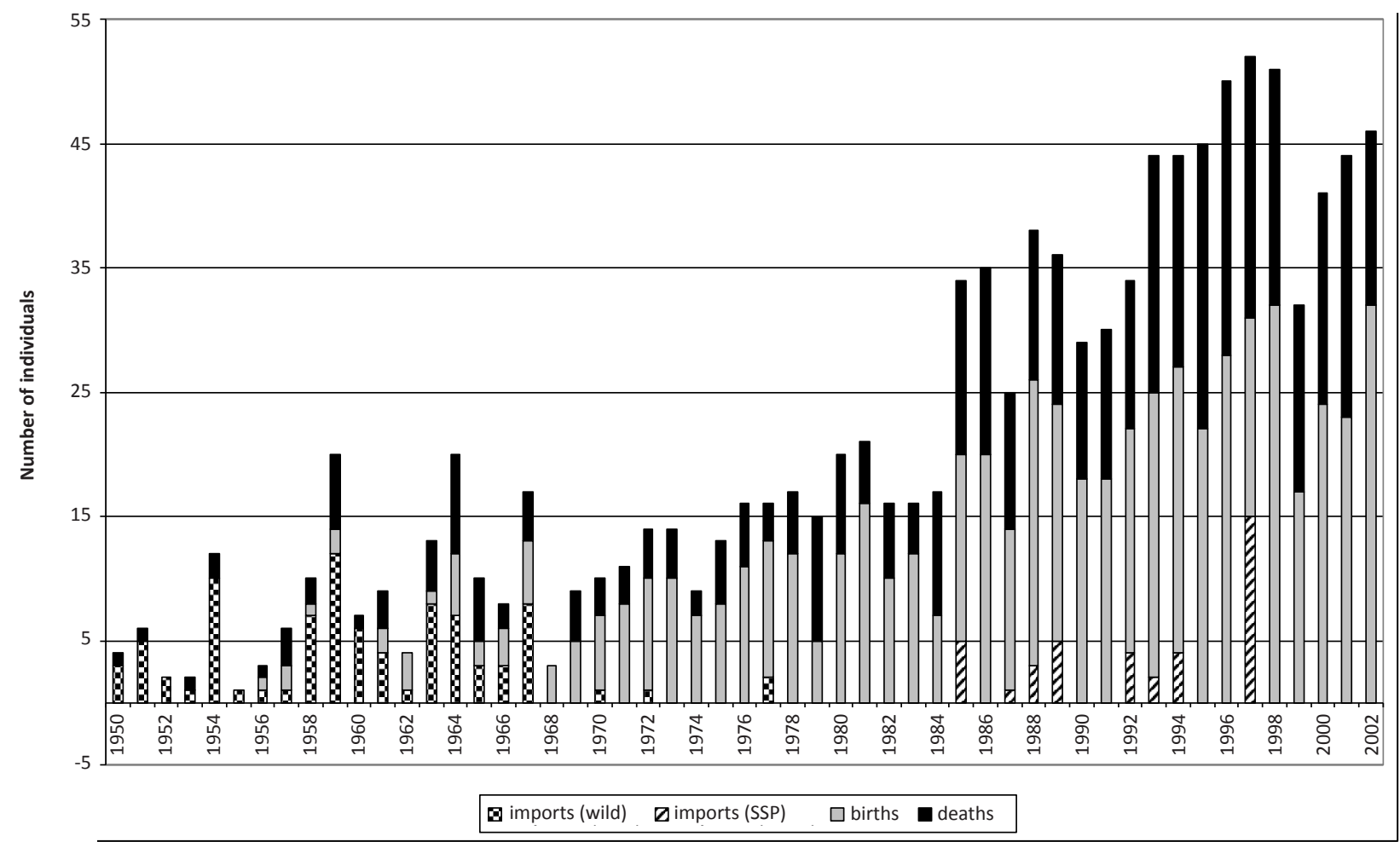

Figure 3. Development of the EEP population with reference to births, deaths, exports and imports (see Kaumanns et al. 2006)

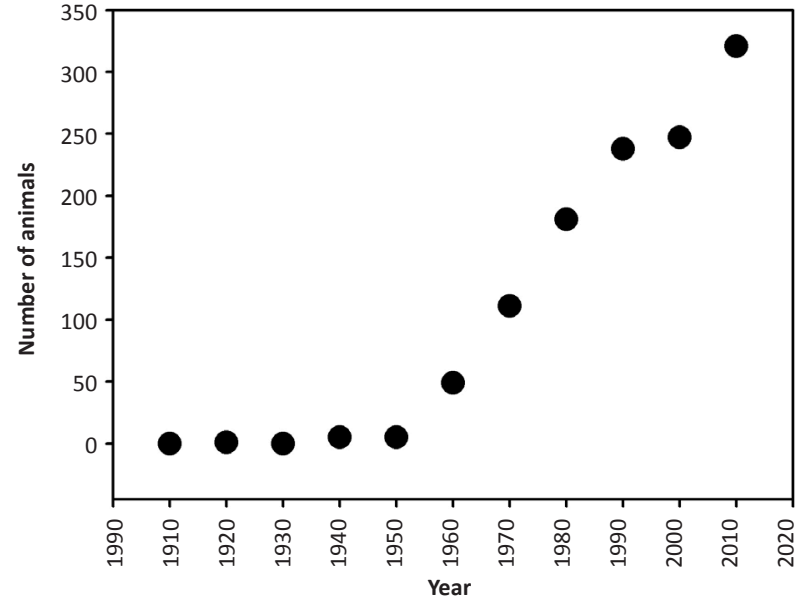

Figure 4. Development of the European lion-tailed macaque population between 1950-2011 (see Sliwa 2011)

females over years and a birth interval of two to three years, the mean number of births per year was low. As has been described earlier (Kaumanns \& Rohrhuber 1995; Kaumanns et al. 2001, 2006), the females, starting with the founder generation in the 1950s and continuing till now, vary considerably in reproductive output. On an average, during the period between 1990 and 2002, only about $30 \%$ of potentially reproductive females gave birth to surviving offspring (Kaumanns et al. 2008). Since most groups in the European population were one-male units, it is evident that the mean contribution of the males to reproduction was much lower than that of the females. Overall, the data available on the reproductive output of females and males suggest that the effective population size in the European Lion-tailed Macaque population is far below the population size (Kaumanns et al. 2006).

\section{ANALYSIS OF BREEDING PROGRAMS}

Since the 1980s, most of the captive Lion-tailed Macaques were included in the breeding programs. This led to a more systematic and conservation-oriented management above the level of individual institutions. It was expected to increase productivity and to achieve sustainability. The following more detailed analysis of the captive Lion-tailed Macaque population will, therefore, focus on these 30 years (1980-2010) of its history covering about six generations, and it will ask whether the two large programs achieved their goals. Table 1 provides an overview of the programs.

As it is obvious from Fig. 1, the American population showed a $100 \%$ increase in size already in the decade prior to the establishment of the SSP in 1981, and during the first decade of the program, the population almost doubled again (Lindburg \& Gledhill 1992). In 1988, there were 268 individuals recorded. This productive early 
Table 1. Breeding programs and status for the Lion-tailed Macaque

\begin{tabular}{|c|c|c|c|c|c|}
\hline Program & Year of establishment & $\begin{array}{c}\text { Starting number of } \\
\text { individuals }\end{array}$ & Number of births & $\begin{array}{c}\text { Year of last census } \\
\text { individuals }\end{array}$ \\
\hline North America/SSP & 1980 & 163 & $1999-2007: 8$ & 2012 \\
\hline Europe/EEP & 1989 & 89 & $1997-2007: 200$ & 2011 & $343(145.180 .18)$ \\
\hline India & 1996,2001 & $60(?)$ & $?$ & 2012 \\
\hline
\end{tabular}

? Exact numbers are not available

period of SSP management was followed by a period of continuous decline. In the last eleven years, there have only been six surviving infants (Ness 2011). The European population, too, was growing already in the years before the EEP was started in 1989, and it grew continuously since then (Fig. 3). The EEP recorded more than 200 births in the last 10 years (Sliwa 2011).

There were several attempts to establish a breeding program for the Lion-tailed Macaque in India, its country of origin. Indian zoos, however, have failed in establishing the necessary organizational and infrastructural conditions for a successful management so far (Krishnakumar \& Manimozhi 2000; Singh et al. 2012). The historical population in Indian zoos between 1940 and 2010 comprised 273 individuals (Malviya 2011). About $40 \%$ of these were (and are) wild caught. The actual captive population of about 65 individuals is widely scattered over many zoos and seems to be of low viability; breeding is rare. About $50 \%$ of the holders keep unisex groups only. Additionally, small numbers of Liontailed Macaques are kept in Japan, Australia, Singapore, Korea, Malaysia, Mexico, and China. They are managed on a national level. Due to their small numbers, however, they do not play a substantial role as subpopulations but may contain important genetic material.

\section{Problems and management Strategies IN THE BREEDING PROGRAMS}

A national breeding program for the Lion-tailed Macaque was initiated by the American zoos in 1980 because according to Hill (1971), the species was classified as threatened with extinction in the wild and a captive population was planned as a reserve. To reach this goal, the status of the zoo population needed improvement, which was attempted by establishing an Endangered Species Breeding Program (Foose \& Conway 1985). A comprehensive volume reports the efforts made to optimize the management of the population (Heltne 1985).

In his first analysis of the status of the captive population of Lion-tailed Macaques for the time period 1971-1977, Lindburg (1980a) identified the low number of births as an important reason for the poor status of this endangered species in zoos. According to him, less than $25 \%$ of the potentially reproductive females gave birth to infants, and a significant percentage of the latter died soon after birth. A high proportion of non-breeding adult females is a pattern which has characterized the captive Lion-tailed Macaque populations since then. It has been regularly noted in reports and publications and was discussed in all international meetings both for the SSP and the EEP population (SSP: Lindburg 1980b; Lindburg et al. 1989, 1992; Melnick 1990; EEP: Kaumanns \& Rohrhuber 1995; Kaumanns et al. 2001). These authors also point to high infant mortality as the second key pattern of the captive Lion-tailed Macaque populations. It seems that the highest proportion of deaths in captive Lion-tailed Macaques is due to mortality in the first weeks of life (Lindburg et al. 1992; Kaumanns \& Rohrhuber 1995; Lindburg 2001). Breeding problems were discussed during the international meeting on the Lion-tailed Macaque in San Diego in 1990 as a critical factor for the survival of the global captive population. Appropriate social management was emphasized as a means to reduce breeding problems (Melnick 1990).

In the years after the San Diego meeting, however, in the two large breeding programs, management strategies developed with different goals. In the case of the EEP, establishing a large population was regarded as an important goal per se and a minimal size of about 400 individuals was recommended based on behavioural and social concerns. In the case of the SSP, increasing the population size was also propagated in the earlier period of the program. Conway (1985) proposed 500 individuals necessary for a "save" population. Lindburg (2001), however, stated that in the mid 1980s, the population already exceeded the 200 spaces that zoos in North America were willing to devote to the species. Although a substantial number of non-reproducing females remained, unexplained breeding problems in the SSP population lost the focus of attention. Mainly due to a lack of spaces and a decreasing number of zoos interested in keeping the species, SSP suggestions and recommendations mainly focused on a reduction 
in population size but at the same time, on the establishment of "hedge breeding" that is, breeding on a scale sufficient to maintain a viable population as a hedge against catastrophic disappearance of the remaining wild population (Lindburg et al. 1997; Lindburg 2001). Fitch-Snyder (1990) reports that following this approach, reproduction was concentrated in selected institutions and the surplus non-breeding individuals were kept at the other facilities. Stable social groups of females were retained by moving only males between institutions. Cross-fostering of infants (which were not related to the "new" mother) was propagated to promote genetic diversity thus increasing the number of non-related individuals in the group. The use of reversible and nonreversible birth control (both for males and females) and the establishment of all-male groups at an early age were recommended. The exclusion of herpes $B$ positive individuals from the breeding population further reduced the effective population size.

It was assumed that the resulting much smaller (but genetically well balanced) population, with many females under birth-control and neutered individuals, remained viable for the purposes of "hedge breeding" and could be enlarged by "switching on" reproduction again if needed (steady- state maintenance, see Lindburg et al. 1997; Lindburg 2001). It seems that the importance of the fact that a significant proportion of the females (and groups) still might have breeding problems was underestimated. In any case zero population growth was desired and therefore only few "new" infants per year were recommended. However, Lindburg (2001) pointed to the possible negative consequences of steady-state breeding for social and demographic structures. As a consequence of "steady-state policy", group sizes decreased. Lindburg (1992) stated that most institutions had groups with less than seven members because young males were removed early and kept separately to avoid social conflicts. According to Ness (2011), about 75\% of the actual institutions keep less than five individuals. "Steady-state breeding" indeed led to a strong decrease in population size. From 163 Lion-tailed Macaques in 1980 and 268 individuals in 1988, population size dropped to 88 individuals in 2011, with most of the latter probably being non-reproductive (Ness 2011). Of the 81 current individuals, 28 are non-reproductives due to sterilization and six are excluded from breeding due to old age and medical reasons (Carter \& Ness 2012).

In contrast to what happened in the SSP, limiting population size was not recommended for the EEP. "Breeding problems" were regarded as a key topic for the EEP management. Birth patterns were monitored regularly and discussed in the annual reports between 1990 and 2004. The percentage of females that were breeding (30\%) remained low, and infant mortality remained high (Kaumanns et al. 2006, 2008). A small proportion of the females gave birth to a large proportion of the infants (Kaumanns et al. 2001). The annual EEP recommendations focused on aspects of behavioural and especially social management, which were expected to reduce breeding problems. As a key recommendation, the establishment of large groups, by allowing groups to grow continuously, was propagated. Large groups were expected to provide better social and socialization conditions. The absolute number of larger groups grew (Table 2). The number of groups with a minimum of five members increased from 7 to 26 between 1989 and 2011. However, the percentage of such groups increased only marginally.

Since large groups and stability in group composition and social relationships were propagated, removals and transfers of individuals between groups were done only to prevent inbreeding and/or to establish new groups. Between 1990 and 2004, a total of 167 Lion-tailed Macaques were transferred: $119(81,38)$ individuals were transferred within the EEP and 48 came from or went to non-EEP institutions.

The EEP population, with a mean of about $10 \%$ increase in the number of individuals per year between

Table 2. Group size and number of groups under EEP

\begin{tabular}{|c|c|c|c|}
\hline Year & $\begin{array}{c}\text { Number of } \\
\text { groups }\end{array}$ & $\begin{array}{c}\text { Number with 5+ } \\
\text { individuals (\%) }\end{array}$ & $\begin{array}{c}\text { Number } \\
\text { with10+ } \\
\text { individuals (\%) }\end{array}$ \\
\hline 1989 & 13 & $7(53.8)$ & $3(23.0)$ \\
\hline 1990 & 13 & $9(69.2)$ & $3(23.9)$ \\
\hline 1991 & 17 & $11(64.7)$ & $4(23.5)$ \\
\hline 1992 & 26 & $18(69.2)$ & $4(15.8)$ \\
\hline 1993 & 27 & $15(55.5)$ & $6(22.2)$ \\
\hline 1994 & 27 & $16(59.2)$ & $6(22.2)$ \\
\hline 1995 & 29 & 15 (51.7) & $2(6.8)$ \\
\hline 1996 & 29 & $17(58.6)$ & $4(13.7)$ \\
\hline 1997 & 32 & $22(68.7)$ & $3(9.3)$ \\
\hline 1998 & 31 & $22(70.9)$ & $7(22.5)$ \\
\hline $1999 / 2000$ & 38 & $22(57.8)$ & $7(18.4)$ \\
\hline 2001 & 41 & $19(46.3)$ & $7(17.0)$ \\
\hline 2002 & 41 & $22(53.6)$ & $8(18.5)$ \\
\hline 2004 & 42 & $23(54.7)$ & $8(19.0)$ \\
\hline 2007 & 44 & $25(56.8)$ & $8(18.0)$ \\
\hline 2010 & 42 & $27(64.2)$ & $11(26.1)$ \\
\hline 2011 & 43 & $26(60.5)$ & $13(30.2)$ \\
\hline
\end{tabular}


1990 and 2002 (Kaumanns et al. 2008), grew only little but steadily (Fig. 3).

\section{Metapopulation management}

A key outcome of the San Diego meeting in 1990 was a global five-year action plan (Chivers 1990) that referred to the important topics and goals of Lion-tailed Macaque conservation. Similar to previous meetings, the need for more field studies was emphasized. The field studies should generate more knowledge about the biology and especially the reproductive biology of the species, which was expected to help solve breeding problems. A better international cooperation between the larger programs and the Indian zoos was also strongly recommended. In the years after 1991, international cooperation was mainly realized via further international congresses. Experts both from the wild and from the zoos met, exchanged information and discussed the problems of the populations. The exchange of ideas and data concerning captive management, however, did not lead to a unified management that would have covered all captive and wild populations. As has been described above, SSP and EEP even developed divergent "management policies". Both programs, however, supported field studies by providing funds and supported Indian zoos by providing know how and training opportunities. The annual EEP reports since 1995 reflect a growing tendency to consequently discuss matters of the EEP population in the context of the global captive and wild population. Especially the EEP husbandry guidelines (Kaumanns et al. 2006) explicitly used new results from field studies, particularly with reference to the social system and to reproduction, to refine or support the recommended keeping systems. On the other hand, data from the captive side, e.g., on the hormonal system and reproduction (for a summary see Lindburg 2001), contributed to basic biological knowledge of the species and to the development of field studies. A real metapopulation management, combining in situ and ex situ programs for the global Lion-tailed Macaque population, however, was not developed.

\section{DISCUSSION}

The aim of this paper was to review the development and the management history of the captive population of the Lion-tailed Macaque in order to identify management patterns that might have contributed to its actual poor status in terms of breeding potential. The overall analysis of the development of the global captive population of Lion-tailed Macaques revealed problems and negative trends. The living component of the (global) historical population in 1980 was transferred into two larger breeding programs, and it comprised about 350-400 individuals. Within about 30 years, it developed towards a global population of about 500 individuals. Nearly $70 \%$ of them are part of the European population. At least $25 \%$ of the current global population, including the SSP population, are probably non-reproductive. The integration of a large proportion of the captive population into international endangered species breeding programs evidently supported the survival of the species under human care so far, but did not lead to a possibly sustainable global captive population sensu Lacy (2013). Among the living populations, only the EEP population is significantly larger now than when the program started and showed a decent number of births in the last 10 years. According to Sliwa (2007), a "gene drop analysis" showed that the population retained a gene diversity of $96 \%$ of the founder population. Whereas this population seems to have the potential for further breeding and sustainability, the other populations are not likely to survive without input from outside and new management programs. The European population, which constitutes the main and still productive part of the global population, started in the 1950s. The European population had 56 founder females and 47 founder males. Only $39.3 \%$ of these wild caught females and $31.9 \%$ of these wild-caught males reproduced (Krebs \& Kaumanns 2002). Probably more than 100 other potential founders in the other populations and hundreds of potentially productive captive-born individuals could not contribute to a global reserve population because "their" populations did not survive or were "managed" to a non-productive status.

What are the shortcomings of the breeding programs for the Lion-tailed Macaque? The analysis of their management history does not provide simple answers as illustrated below.

The analysis is confronted with differences in management policies which make it difficult to compare their results and to identify common reasons for the problems. After a decade of population growth in the American population, the latter was managed to shrink. In contrast to this, the European population was managed to grow continuously. The low reproductive potential of the current American population with its few remaining potentially fertile, though ageing, individuals, was certainly not intended. It rather developed as a consequence of processes triggered by an already small and demographically reduced population with an artificially induced low effective population size. Group sizes in the SSP population became much smaller 
than mean group sizes in the wild. It is evident that in these groups the demographic structure was simple and the generational overlap low. Due to transfers of individuals between groups, social stability may have temporarily been low. Social relationships may also have been negatively influenced by hormonal birth control measures. The behaviour, the social competence and the reproductive potential of individuals growing up and living under these altered conditions were likely to be changed and negatively influenced. The resulting, possibly behaviour-induced, variance and decrease in breeding success might have led to a further and unwanted reduction in effective population size (see Anthony \& Blumstein 2000). Following Carroll \& Watters (2008), it is possible that the strongly modified social and non-social environment affected the reproductive success of phenotypes and the fitness of genotypes. The low productivity in the shrinking SSP population in the last decade also may be regarded as an expression of demographic and environmental stochasticity. Demographic stochasticity involves random fluctuations in vital rates at the individual level (for example deviations from the mean number of offspring) and arises from the fact that individuals are discrete entities (Brook 2008). According to Brook, small populations are specifically vulnerable to stochastic hazards. The removal of a significant number of Herpes $B$ positive individuals from the SSP population, and a strong decrease in the number of holding institutions due to "loss of interest" (Lindburg 2001) might be discussed in the role of such hazards. Overall it seems possible that the viability of the Lion-tailed Macaque SSP population decreased as a consequence of a management-induced strong reduction in population size (as a reaction to a lack of spaces) and of the resulting drastic changes in some of the life history patterns like group size and in a number of behavioural systems. Possibly, these conditions hindered the establishment of a sufficiently large effective population size as necessary for the survival of a population. Anthony \& Blumenstein (2000) demonstrated for a number of different animal species how the behaviour of individuals, especially in small and altered populations, could reduce effective population size and thus contribute to their threatened status.

Although it was managed without putting limits to population size, the European and specifically the EEP population also did not develop optimally (Singh et al. 2009). The slow but steady increase in population size that occurred was determined by births and deaths, but was also supported significantly by imports from other populations and later by the integration of new
EEP participants. The increase in population size would have been significantly lower without input from outside. The increase was realized in spite of a low effective population size with a contribution of only about 30 to $40 \%$ of the potentially reproductive females to breeding. As a DEMOG (Demographic Modelling Software) analysis (Bingaman \& Ballou 1997) revealed, this increase will continue but remain slow over the next two decades (Kaumanns et al. 2006).

Although the EEP population of the Lion-tailed Macaque has grown to a considerable size in comparison to other captive primate populations (Kaumanns et al. 2008), its actual status cannot be regarded as robust and safe against the risks described above. Under the given condition of slow population growth, seemingly minor events like the loss of a few of the most productive females or the exclusion of breeding groups due to institutional or medical reasons can have serious consequences for the productivity of the population. If effective breeding size is low and the differences between the females in terms of reproductive output are large and unpredictable, even a population of several hundred individuals may not be safe against a serious loss of viability within short periods of time. A decrease in viability, however, may remain undetected for some time, especially when many females are under birth control or when the reproductive output of the individual female is not monitored continuously.

Comparing the development of the two populations under the aspects discussed above, it seems likely that the actual status of the EEP population essentially was supported by a management that kept population size and structure above a critical minimal threshold (sensu Snyder et al. 1996). Furthermore, that status might be specifically supported by the fact that it comprised an increased number of large groups with possibly more natural socialization conditions.

The development in both EEP and SSP populations, however, shows that breeding Lion-tailed Macaques in captivity to establish a self-sustaining reserve population could not be carried out efficiently. It has not generated a safe captive status so far. It seems that under the captive conditions realized so far for the production of one offspring Lion-tailed Macaque, minimally two or three adult females are needed due to several females not reproducing and long inter-birth intervals in reproducing females. Therefore, a large reserve of adult females is required for a substantial population growth.

In wild Lion-tailed Macaque populations, there is a slow turnover (late maturity, long birth interval, low number of infants per female lifetime; Singh et al. 2006). Such life history patterns are difficult to handle for the 
manager of a small captive population. Furthermore, in combination with much unpredictable variation in terms of reproductive output under captive conditions, these patterns are even more challenging. As long as the reasons for individual differences are not known, the problem will remain pending. It is especially at this point where the breeding programs for the Lion-tailed Macaque do not succeed. This is puzzling, since from the establishment of the breeding programs, the status of the knowledge about the biology of the Lion-tailed Macaque has improved continuously. Due to a large number of field studies (Singh et al. 2009) and also many captive studies (Lindburg 2001), the Lion-tailed Macaque is one of the best-studied macaque species by now. The availability of biological knowledge therefore so far does not seem to have contributed much to improving the status of the species, both in situ and ex situ (Singh et al. 2006; Singh et al. 2009).

The problems influencing the development of both captive populations, and in particular the development of the American population, point to the need for stonger application for the principles of adaptive management (Walters \& Hilborn 1978; Walters 1997). Following these authors, conservation management with its usually poor data base and tentative concepts requires a continuous analysis of what has been achieved so far, thus enabling the manager to correct and improve if necessary.

It appears that a too strict and rigid management of populations of wild animals in captivity without controlling its effects, especially when a lack of spaces in zoos favours very small populations, can increase the risk of inappropriate management decisions. They may have fatal consequences for long-term survival of the population. Lacy (2013) proposed that "instead of trusting that all forms of adaptive variation will be maintained along with the modelled neutral genetic variation, we will need to monitor morphological, behavioral, and physiological variation". He also warned that a mere retaining of genetic diversity alone does not necessarily ensure that all the other characteristics of the conserved populations will also be protected adequately. Lees \& Wilcken (2009) showed that a large proportion of zoo populations are in poor shape and are not achieving the conditions for sustainability, a fact that should be critically discussed with reference to the management practices used.

In conclusion, the analysis of the development of the global captive population of the Lion-tailed Macaque and its subpopulations indicates that management strategies as well as some of the management tools used so far require improvements and change of perspectives. Effective population size in the remaining living population is still low, and it is still not known why a large proportion of the females do not reproduce successfully. These problems can be found in the majority of captive primate populations and possibly in other mammals (Kaumanns et al. 2008). The scale and the nature of the problems speak against Lees \& Wilcken's (2009) assumption that "the scientific basis for captive population management is sound" and "therefore, if programmes are failing, it is likely to be either because the science is not being appropriately translated into management recommendations or because those recommendations are not being implemented within institutions". It rather seems likely that the poor status of many populations indicates serious deficits in the management programs themselves and that there is a strong need to reassess the basic scientific approach chosen by the zoo community for the management of captive populations (see also Lacy 2013).

A new management approach for primates might put more emphasis on the perspective that captive primate populations could be regarded as a special case of fragmentation (Kaumanns et al. 2008). The resulting theoretical and practical consequences should become the basis for conservation-oriented management concepts and husbandry systems. For the Lion-tailed Macaque, this is specifically indicated since fragmentation and alterations of habitat and populations are regarded as the main problems for its conservation and hence its survival in the wild. A new approach, therefore, should refer to conservation management as recently propagated for and practised in threatened wild populations. An outline of such an approach is presented below.

\section{MANAGEMENT OF POPULATIONS UNDER ALTERED CONDITIONS: GENERAL CONCEPTUAL FRAMEWORK}

With special reference to the conservation of wild populations of animals under fragmented and altered living conditions, recent studies and new approaches in conservation biology led to the propagation of a conservation management which, besides dealing with populations and their habitats as a whole, is consequently more focused on the status and management of individuals and the phenotypes within the populations in question (Carroll \& Fox 2008). Individuals have to survive and reproduce. The phenotype is the unit of selection. Consequently the phenotype as a whole needs to be managed. According to Carroll \& Watters (2008), "intense management of phenotypes can enhance effective population size and thereby protect viability and genetic 
variation". The term 'phenotype' here refers to the total appearance of an organism resulting from the interaction of the genotype and the environment and includes its traits on the level of morphology, development, physiology, phenology, behaviour and products of behaviour. The stronger focus on the individual and its living conditions are also propagated by Lomnicki (1980), who suggested to students of population dynamics not to look at the average individual in a population but to look for differences between the individuals and try to find out how these differences affect the individual's reproduction and survival (see also Kaumanns 1994). This focus evidently requires much knowledge about patterns and mechanisms of behaviour and their physiological and hormonal correlates on a proximate level. Individual and phenotype-oriented management emphasizes that adaptation to rapidly changing and altered living conditions is more likely to occur under conditions of sufficient 'phenotypic variability', that is when a variety of types of individuals and a variety of traits in which individuals differ provide a larger spectrum of solutions to the emerging problems (Carroll \& Watters 2008).

The management of captive populations of wild animals with their sometimes extremely altered and fragmented living conditions and resulting breeding problems, evidently needs even more focus on the individual and its phenotype as a whole. In contrast to the management programs commonly used for zoo populations, this requires approaches that do not mainly focus on genetic variation and its distribution through the population. Instead, the new programs intend integration of management of genetic variation into a complex management concept as introduced above. It is an accepted fact that a population can become endangered by mismanagement at the level of genetics, for instance, inbreeding. However, it is equally ignored that a population can as well become endangered by inappropriate management on the level of individual and social behaviour, since these traits are also subjected to selection and influence survival of individuals and populations. Therefore, a key area of management would be the behaviour of individuals, its influence on the development and viability of the population and its management with special emphasis on the social behaviour in the case of primates (see Anthony \& Blumenstein 2000; Gosling \& Sutherland 2000; Singh \& Kaumanns 2005). In many cases like the Lion-tailed Macaque, the functioning of the reproductive system is a critical aspect (Singh et al. 2006). In principle, behavioural management aims at creating living conditions such that they facilitate the expression of a full range of adaptive behaviours in individuals and optimize life-history patterns of a species as in their more natural habitats (Kaumanns et al. 2008). This approach has to include much more than enrichment programs.

Altered wild habitats, and even more the limited and altered conditions of captivity, do not allow control and optimization of all the relevant factors for management purposes. Management programs, therefore, have to identify and select key traits (sensu Carroll \& Watters 2008). Orientation as to which key traits and minimal conditions have to be met for the long-term survival of a captive population, besides others, might be developed with reference to specific life history patterns like group size, demographic structure of groups and populations, birth rate, etc. These patterns refer to key aspects in an organism's life. They are shaped by natural selection, reflect patterns of a species' adaptive potential and 'act' as 'interface' between individuals and populations.

Many of the relevant traits are probably rather conservative and inertial and act as constraints on social interactions and mobility. Management and husbandry systems should allow their realization as far as possible: the differences between captive conditions and wild conditions should be kept as small as possible. Managers should start designing keeping systems from optimal conditions, and assess how far they can reduce and alter from there, without violating the limits of adaptive potential. If living conditions do not allow the expression of basic social and other behavioral traits, it may lead to stress and possibly negatively influence reproduction. In particular, suboptimal social conditions may show effects in the short run such as failure of a female to reproduce or to competently rear infants, or in the long run, such as high reproductive variance among individuals. A management that provides recommendations and living conditions that allow a population to realize specific life history patterns (e.g., group size and composition) also facilitates its long-term survival. This approach would include the establishment of a certain range of variance between parameters in individuals, groups and subpopulations and thus would contribute to the 'production' of a variety of individual phenotypes and individual differences as referred above. According to Lacy (2013), "most species will need more, not less, adaptability in the future, and populations being managed as reservoirs for species conservation will often have to be the source of that restored variation".

The following section intends to use this approach and the results of the review of the Lion-tailed Macaque management history presented above to outline principles and recommendations for the captive 
management of the Lion-tailed Macaque that may supplement the existing management concepts.

\section{THE LION-TAILED MACAQUE}

For the management of Lion-tailed Macaques under captive and other altered conditions, the following traits and life history patterns are proposed to be key traits (sensu Carroll \& Watters 2008): The Lion-tailed Macaques live in groups with a modal group size of 1317 individuals in contiguous forests, whereas in forest fragments the size varies from six to 53 individuals (Singh et al. 2002). Adult male to female ratio is $1: 2.11$ and adult to young ratio is 1:0.84. A group may remain stable over generations and decades. The Lion-tailed Macaque society is 'female-bonded' and the females form the permanent core of the group. The females remain in their natal groups whereas adult males migrate among groups. The immigration of an adult male into a group might result in agonistic interactions with the resident male(s), but the adult females appear to prefer the migratory male to the resident male in all their social interactions, including mating (Kumar et al. 2001). Adult males are highly intolerant towards each other (Kaumanns \& Singh 2012). All-male groups have not been found (Singh et al. 2011). The group members are largely dispersed during the day, and social interactions, as compared with many other macaque species, are more infrequent. The social interactions between adult females and adult males are scarce, and between adult males (if there is more than one in the group) almost absent (Singh et al. 2011). A group has a home range of several square kilometres, and in contiguous forests, the home ranges of several groups overlap. Frequent intergroup encounters occur in the overlapping areas.

In the natural habitats, births are observed almost throughout the year. However, there is a peak from January to April (Sharma et al. 2006). In captivity, births occur almost at the same rate over all months (Lindburg et al. 1989; Krebs \& Kaumanns 2001, 2002). The female age at first birth is about 80 months in the wild (Kumar 1987) and about 48 months in captivity (Lindburg et al. 1989; Krebs \& Kaumanns 2001: 65.2 months). The interbirth interval in the wild is about 30 months and infant survivorship is about 0.87 (Kumar 1987; Sharma et al. 2006). Adult males tend to follow females showing sexual swellings. These "consort pairs" often stay away from the rest of the group. Adult females and juveniles are often observed disrupting a mating pair. In the Lion-tailed Macaque, a Multiple-Mount-to-Ejaculate (MME) system is found. The males take fewer mounts to ejaculate when females show swellings, and during the deflated phase, the mounts hardly ever result in ejaculation (Sharma et al. 2006). Individuals are highly dispersed during foraging (Kumar 1987; Krishnamani \& Kumar 2000; Kumara et al. 2000).

Free-ranging Lion-tailed Macaques have a diverse diet, including a large variety of fruits and seeds. Depending on seasonality, fruits are selected only with a specific level of ripeness. Lion-tailed Macaques also feed on a variety of invertebrate fauna, and sometimes even on vertebrates including young birds, lizards, frogs and mammals to the size of the Indian Giant Squirrel Ratufa indica. Many food items require processing, which makes foraging time-consuming. It seems that under the ecological conditions under which Lion-tailed Macaques live, the populations have reached the carrying capacity of their habitats. The subpopulations studied so far did not grow. Lion-tailed Macaques show a slow turnover with few infants per females' lifetime, large birth intervals and low infant mortality. Lion-tailed Macaques are almost wholly arboreal. They are generally observed at a height between 10 and 30 meters and move horizontally through contiguous middle and upper canopy levels of the forest. Travel distance per day could be as much as three kilometres. In the highly fragmented patches of rainforests at the Valparai Plateau in the Western Ghats, the population, monitored over a period of 16 years, increased only in two groups but remained stable in several other groups (Umapathy et al. 2011). An in-depth analysis of population dynamics in a forest fragment showed that almost all females bred continuously over two breeding periods, thus contributing 29 offspring with nearly $90 \%$ survivorship, but the number of adults increased only by four and the number of subadults remained almost the same (Krishna et al. 2006). This brings out several important points regarding the population dynamics in wild Lion-tailed Macaques: most of these populations have probably already reached the carrying capacities of their habitats; the growth rate may be near zero but births occur every year, maintaining fairly constant age-sex ratios; most of the deaths appear to occur at the late juvenile or subadult stage in both males and females.

In agreement with Lindburg (1992), a key recommendation for the captive management of the Lion-tailed Macaque, is therefore that groups comprising of minimally 10-20 individuals with an agesex composition close to that in the wild should be maintained. Such groups are therefore proposed as the most important and indispensable elements of a captive population, since they are likely to provide the appropriate social and especially socialization conditions 
for the production of adaptive individuals. It is necessary, however, that these size and demographic structures are prevalent in a group over as many years and generations as possible and that the absolute number of such groups is as high as possible. Furthermore, to initiate, stimulate, and facilitate social dynamics, especially with reference to male-female relationships, to the reproductive system and to male exchanges, as many institutions as possible should keep two groups of Lion-tailed Macaques each in adjacent enclosures ("multi-group approach"), thus allowing controlled mutual stimulation and 'group encounters' (see experimental group encounters described by Kaumanns et al. 1998; Zinner et al. 2001). Since male migration is a frequent and important aspect of Lion-tailed Macaque social organization, the periodic exchange of breeding males in captive groups is required not only to avoid inbreeding, but also to stimulate social life.

It is assumed that these complex keeping systems with their resulting multitude of social processes and problems would provide the necessary conditions for the realization of species-specific behaviour patterns and would support the development of different types and traits of individuals, as is necessary, following Carroll \& Watters (2008), for a population that has to cope with the altered conditions of captivity.

It is evident that the recommended large social groups require large, variable and flexible enclosures, which not only provide the appropriate spatial conditions (necessary as medium for social activities and processes), but also support the development of complex cognitive and manipulative skills as described for Lion-tailed Macaques (Westergaard 1988). To develop the required phenotypic variability at population level, as many groups and keeping systems of this kind as possible should be established. Only this population as a whole is likely to produce individuals with the behavioural and social competencies as required for the establishment of a viable population with predictable patterns of reproduction and a high effective size.

However, it is difficult and time-consuming to start from a small demographically poor population to reach this status, as has been observed in the European population. This seems to be a consequence of the slow 'turnover' from one generation to the next, which determines population dynamics in Lion-tailed Macaques. The life history patterns in the wild result in a 'slow' but so far evidently adaptive 'turnover' and a stable population. The life history patterns in the historical captive populations also resulted in a slow turnover, but evidently did not lead to a population with a potential to survive. A more close comparison reveals that the factors that lead to slow growth may differ considerably between wild and captive populations. It seems that in the wild, the majority of the adult females reproduce but produce few infants per lifetime, show large birth intervals and are older at first birth. Infant mortality is low. In captivity, fewer females breed. They produce many infants per lifetime, have lower birth intervals, are younger at first birth, and experience high infant mortality. This pattern in captivity, as has been shown above for the SSP and the EEP populations, leads to an unbalanced population structure. It can negatively influence genetics, demography, and social structures, with the risk of a growing difference between population size and effective population size, and a loss of viability. It hinders the establishment of the breeding conditions as recommended above, thus producing a vicious circle.

As a consequence, for the development of a management program for Lion-tailed Macaques, and possibly other primate species, the first critical step is to establish procedures that lead to the breeding conditions described above. In this initial period the population has to grow as fast and as much as possible. Generation time should be as short and generational overlap in groups as strong as possible. It is evident that during this period of improving a population's productivity, birth control and other measures to control population size can be counterproductive. Judging from the development of the EEP population, this initial period can last for more than 20 years.

Slow growth in the captive Lion-tailed Macaque population is a consequence of the low mean reproductive output per female, but to a certain degree also a consequence of (necessary) management procedures, which hinder or delay the growth of groups. The latter include the frequent (more or less disruptive) exchange of breeding males for genetic reasons (inbreeding avoidance, etc.), the (too) early removal of juvenile males, and the removal of females for the establishment of new heterosexual groups. Even if these procedures are necessary due to the limited captive conditions, they can lead to long-lasting social imbalances and stress and therefore may result in breeding problems. More appropriate keeping systems (multi-group approach) would help to reduce these imbalances and may facilitate achieving social stability. In agreement with Lindburg (1992), it is also indicated to support the further growth of larger groups rather than taking clans of females out to establish new groups. In continuously growing groups, the generational overlap is likely to be higher, thus providing richer conditions for socialization. It may 
happen that an accidentally male-biased reproductive output in a group over years can force the manager to reduce group size significantly by removing these males before they start mating with related females. In these cases, related juvenile and subadult males should when possible, be removed as cluster rather than individually. This provides a chance to keep these males together for a few years, thus reducing the surplus males problem. Due to high a- priori incompatibility, unfamiliar adult males in Lion-tailed Macaques probably cannot be kept in unisex groups (Singh et al. 2011; Kaumanns \& Singh 2012).

Terminating the initial phase of a breeding program for Lion-tailed Macaques and starting a second management period is indicated when the growth rate is constant and when breeding patterns are predictable (see also Foose et al. 1986). It is only then that population management can consider keeping population size and structure on a more stable level. Since under captive conditions mortality induced by predators, food shortage and other ecological factors are absent and therefore do not contribute to limiting population growth, the only means to achieve this would be controlling, and possibly reducing, the reproductive output of the females, such that the turnover rates allow only minor population growth. Euthanasia would be another means but is not permitted and/or accepted in many countries. In principle, birth control in individual females has to be done such that it does not negatively affect the social environment, socialization conditions and thus the reproductive system at population level. To achieve appropriate variance in reproductive output, the latter needs to be manipulated accordingly both per individual and between individuals and groups. Groups have to remain demographically diverse, with a rich enough spectrum of partners, within the group itself and between groups in "multi groupsetups", as propagated above. Various means to reduce the number of offspring include: (a) prevent fertilization directly via contraceptives, and (b) prevent fertilization indirectly via manipulation of social conditions. Only in groups with more than 25 individuals could females along matrilines be removed to establish new groups. Removal and integration of individual females into new groups is counterproductive since it disturbs the demographic and social patterns in a female-bonded social system.

Evidently, many subadult and adult Lion-tailed Macaque males cannot be permanently kept in breeding groups. In the wild, groups of Lion-tailed Macaques usually have only one adult male, but additional male(s) keep making attempts to enter them, since male migration is a common phenomenon. Males may remain solitary for some time, and hence, may face higher predation and are a part of the food chain. Since euthanasia is often not accepted as a management technique for ethical reasons and/or by legislation (see euthanasia statement approved by EAZA Council on 26 September 2011), extra group management of males is inevitable. A male may be kept in a separate enclosure but in visual contact with the group for a possible future replacement of breeding males. A castrated male could also be retained in the natal group over some period of time as personal observations by WK show. Whether several castrated males can be kept in an all-male group has not been investigated. Castration, however, should be carefully considered since a castrated male may not be properly integrated into the group, and the irreversible means to control productivity may turn out to be counterproductive in the long run.

Since the function of a captive breeding population is to provide the conditions and 'materials' for successful reproduction in a species that itself depends on the behaviour of individuals and on the quality of the breeding units as has been discussed, the (target) size and structure of the captive population has to be defined from this end in combination with genetic considerations. It would be against the logic of phenotype-oriented management to fix size and structure first with reference to available spaces in zoos, only hoping that sustainability emerges. Based on the analysis of the global historical population and the considerations presented in this paper, it is postulated that a self-sustaining captive population of Lion-tailed Macaques needs more than a few hundred individuals and should comprise of several large subpopulations that have to be managed as a metapopulation on an international level, with a significant focus on the country of origin, India, and potential reintroductions. A general outline of an integrated in situ and ex situ approach for the conservation of Lion-tailed Macaque was proposed previously (Singh et al. 2009). However, due to lack of institutional support, an international metapopulation management plan has not been produced. It is in this context that the Indian zoos need to develop infrastructure and expertise to prepare the ground for the conservation of the Lion-tailed Macaque in the habitat country by contributing to the global captive population and conservation activities in India, which might include reintroduction. In a recent paper, Singh et al. (2012) elaborate the necessary conditions for successful management of captive populations of primates in Indian zoos.

Many captive primate populations do not appear to be in good shape and have very low chances to develop towards sustainability. Recently emerging views on how to deal with this and to redefine the role of zoos strongly 
propagate stronger links with the conservation of wild populations. Through zoos supporting wild populations, Conway (2011) hopes to "buy time for wild animals". Lacy (2013) propagated achieving true sustainability of zoo populations by much more elaborated metapopulation management, including the wild population. While these approaches are appreciated, they should not hinder zoo biologists from reconsidering captive propagation policies and management plans that have so far lead to the poor status of populations. There is a risk that a large number of captive populations will be of little future use for conservation (Leus et al. 2011). If the Lion-tailed Macaque can be taken as a model for the problems and potential solutions, aspects of the captive propagation of primates emerge that requires significant changes. Much more focus has to be put on individuals and their behaviour in social units. The required size and demography of the population have to be established such that the conditions for successful breeding are realized. This is expected to result in reduction of the difference between effective population size and true population size. Anthony \& Blumstein (2000) demonstrate that this can be an important condition for the survival of populations under altered conditions. Manipulation of the size and structure of captive populations has to strongly refer to these findings. In this regard, the corresponding knowhow needs to be developed.

It is obvious that most captive populations need to be much larger than propagated so far as derived from genetic models alone. Furthermore, living conditions and keeping systems require improvement, especially with reference to the available space. This inevitably would lead to a further reduction in the number of species kept in zoos and a much more focussed approach to their conservation. It seems that zoo biology has to develop new approaches which include a larger spectrum of concepts of biology and knowledge about the adaptive potential of animal species, as developed recently in studies on populations under altered and fragmented conditions.

\section{REFERENCES}

Anthony, L.L. \& D.T. Blumstein (2000). Integrating behaviour into wildlife conservation: the multiple ways behaviour can reduce $\mathrm{Ne}$. Biological Conservation 95(3): 303-315; http://dx.doi.org/10.1016/ S0006-3207(00)00037-9

Bingaman, L. \& J. Ballou (1997). DEMOG4.2: Demogrpahic Analysis Software. National Zoological Park, Wahsington D.C.

Brook, B.W. (2008). Demographics versus genetics in conservation biology pp. 35-49. In: Carroll, S.P. \& C. Fox (eds.) Conservation Biology-Evolution in Action. Oxford University Press, Oxford.
Carroll, S.P. \& C. Fox (eds.) (2008). Conservation Biology-Evolution in Action. Oxford University Press, Oxford, 380pp.

Carroll, S.P. \& J.V. Watters (2008). Managing phenotypic variability with genetic and environmental heterogeneity: Contemporary evolution as a first principle of conservation biology pp. 181-198. In: Carroll, S.P. \& C. Fox (eds.) Conservation Biology-Evolution in Action. Oxford University Press, Oxford.

Carter, S. \& T. Ness (2012). Population Analysis and Breeding and Transfer Plan Lion-tailed (Macaca silenus) AZA Species Survival Plan Yellow Program. Minnesota Zoo and Association of Zoos and Aquariums

Chivers, D. (1990). Action plan for Lion-tailed Macaques: 5-year plan for species management. Lion-Tales 7: 5.

Conway, W. (1985). Saving the Lion-tailed Macaque pp. 1-12. In: Heltne P.G. (ed.) The Lion-tailed Macaque : Status and Conservation. Alan R Liss, New York.

Conway, W.G. (2011). Buying time for wild animals with zoos. Zoo Biology 30(1): 1-8; http://dx.doi.org/10.1002/zoo.20352

Hill, C.A. (1971). Zoo's help for a rare monkey. Oryx 11(1): 35-38; http:// dx.doi.org/10.1017/S003060530000942X

Fitch-Snyder, H. (1990). 1990 midyear Lion-tailed Macaque SSP propagation group meeting. Lion-Tales 7: 8-9.

Fitch-Snyder, H. (2006). International Lion-tailed Macaque Archive Studbook Macaca Silenus. International studbook library from archive data held by ISIS Laurie Bingaman Lackey 04 July 2007

Foose, T.J. \& W.G. Conway (1985). Models for population management of Lion-tailed Macaque resources in captivity (A working paper) pp. 329-342. In: Heltne P.G. (ed.) The Lion-tailed Macaque: Status and Conservation. Alan R Liss, New York.

Foose, T.J., R. Lande, N.R. Flesness, G. Rabb \& B. Read (1986). Propagation Plans. Zoo Biology 5(2): 139-146; http://dx.doi. org/10.1002/zoo.1430050208

Gledhill, L.G. (1987). Lion-tailed Macaque (Macaca silenus) International Studbook. Woodland Park Zoological Gardens, Seattle, 419pp.

Gosling, L.M. \& W.J. Sutherland (eds.) (2000). Behaviour and Conservation. Cambridge University Press, Cambridge, 438pp.

Heltne, P.G. (ed) (1985). The Lion-tailed Macaque: Status and Conservation. Alan R. Liss, New York, 411pp.

Leus, K., L.B. Lackey, W. van Lint; D. De Man, S. Riewalt, A. Veltkam \& J. Wijmans (2011) Sustainability of European Association of Zoos and Aquaria Bird and Mammal Populations WAZA Magazine 12: 11-14.

Kaumanns, W. (1994). The "Quality" of Captive Primate Populations. Primate Report 39: 127-132

Kaumanns, W. \& B. Ruhrhuber (1995). Captive propagation in Liontailed Macaques: The status of the European population and research implications, pp. 296-309. In: Gansloßer, U., J.K. Hodges \& W. Kaumanns (eds.) Research and Captive Propagation. Filander Verlag, Fürth.

Kaumanns, W., C. Schwitzer, C. Klumpe \& P. Schmid (2000). How are primate breeding programs doing? An overview and preliminary analysis, pp. 448-460. In: Rietkerk (ed). EEP Yearbook 1998/99. EAZA Executive Office, Amsterdam.

Kaumanns, W., C. Schwitzer, P. Schmidt \& C. Knogge (2001). The European Lion-tailed Macaque population: an overview. Primate Report 59: 65-76.

Kaumanns, W., D. Zinner \& J. Hindahl (1998). Experimental group encounters as social stimulation for captive Lion-tailed Macaques (Macaca silenus). Zoologischer Garten 68: 45-55.

Kaumanns, W., E. Krebs \& M. Singh (2006). An endangered species in captivity: husbandry and management of the Lion-tailed Macaque (Macaca silenus). MyScience 1: 43-71.

Kaumanns, W. \& M. Singh (2012). Social relationships among Liontailed Macaques (Macaca silenus) in differently structured social units. Current Science 102(10): 1451-1455.

Kaumanns, W., M. Singh \& C. Schwitzer (2008). Primate populations in zoos: A case of fragmentation. Primate Report 76: 41-54.

Krebs, E. \& W. Kaumanns (2001). European Studbook for the Lion-tailed Macaques (Macaca silenus). Zoologischer Garten Köln, Cologne, 
$150 \mathrm{pp}$

Krebs, E. \& W. Kaumanns (2002). European Studbook for the Lion-tailed Macaques (Macaca silenus). Zoologischer Garten Köln, Cologne, 90pp.

Krishna, B.A., M. Singh \& M. Singh (2006). Population dynamics of a group of Lion-tailed Macaques (Macaca silenus) inhabiting a rainforest fragment in the Western Ghats, India. Folia Primatologica 77(5): 377-386; http://dx.doi.org/10.1159/000093703

Krishnakumar, N. \& A. Manimozhi (2000). What ails captive breeding programmes in India - Lion-tailed Macaque (LTM) - A case study. Zoos' Print Journal 16(2): 421-422; http://dx.doi.org/10.11609/JoTT. ZPJ.16.2.421-2

Krishnamani, R. \& A. Kumar (2000). Phyto-ecology of the Lion-tailed Macaque (Macaca silenus) habitats in Karnataka, India: Floristic structure and density of food trees. Primate Report 58: 27-56.

Kumar, A. (1987). The Ecology and Population Dynamics of the Lion tailed Macaque (Macaca silenus) in South India. PhD Dissertation, University of Cambridge, 174pp.

Kumar, M.A., M. Singh, H.N. Kumara, A.K. Sharma \& C. Bertsch (2001) Male migration in Lion-tailed Macaques. Primate Report 59: 5-18.

Kumara, H.N., M. Singh, A.K. Sharma, M. Singh \& M.A. Kumar (2000). Faunal component in the diet of Lion-tailed Macaque. Primate Report 58: 57-66.

Lacy, R.C. (2013). Achieving true sustainability of zoo populations. Zoo Biology 32: 19-26; http://dx.doi.org/10.1002/zoo.21029

Lees, C.M. \& J. Wilcken (2009). Sustaining the ark: the challenges faced by zoos in maintaining viable populations. International Zoo Yearbook 43(1): 6-18; http://dx.doi.org/10.1111/j.1748-1090.2008.00066.x

Lindburg, D.G. (1980a). Status and captive reproduction of the Liontailed Macaque. Internatioal Zoo Yearbook 20(1): 60-64; http:// dx.doi.org/10.1111/j.1748-1090.1980.tb00943.x

Lindburg, D.G. (1980b). Breeding the endangered lion-tailed monkey of India. ZooNooz 53(5): 16.

Lindburg, D.G. (1992). Group size for captive Lion-tailed Macaques. Lion-Tales 8: 4-5.

Lindburg, D.G. (2001). A century of involvement with Lion-tailed Macaques in North America. Primate Report 58: 51-64.

Lindburg, D.G., A.M. Lyles \& N.M. Czekala (1989). Status and reproductive potential of Lion-tailed Macaques in captivity. Zoo Biology (Supplement) 8(S1): 5-16; http://dx.doi.org/10.1002/ zoo.1430080503

Lindburg, D.G., J. laderosa \& L. Gledhill (1997). Steady-state propagation of captive Lion-tailed Macaques in North American zoos: A conservation strategy, pp. 131-150. In: Walli, J (ed.) Primate Conservation: The Role of Zoological Parks. A publication of the American Society of Primatologists.

Lindburg, D.G. \& K.A. Forney (1992). Long-term studies of captive Liontailed Macaques. Primate Report 32: 133-142.

Lindburg, D.G. \& L.G. Gledhill (1992). Captive breeding and conservation of Lion-tailed Macaques. Endangered Species UPDATE 10: 1-4.

Lomnicki, A. (1980). Regulation of population density due to individua differences and patchy environment. Oikos 35: 185-193.

Malviya, A., A. Srivastav, P. Nigam \& P.C. Tyagi (2011). Nationa Studbook of Lion-tailed Macaque (Macaca silenus). Wildlife Institute of India, Dehradun and Central Zoo Authority, New Delhi, 238pp.

Melnick, D.J. (1990). Report on the third Lion-tailed Macaque symposium. Lion-Tales 7: 1-4.

Ness, T. (2011). North American Studbook for Lion-tailed Macaques (Macaca silenus). Minnesota Zoological Gardens, Minnesota, 131pp.

Sharma, A.K., M. Singh, W. Kaumanns, E. Krebs, M. Singh, M. A. Kumar \& H.N. Kumara (2006). Birth patterns in wild and captive Lion-tailed Macaques (Macaca silenus). International Journal of Primatology 27(5): 1429-1439; http://dx.doi.org/10.1007/s10764-006-9077-5

Singh, M., A.K. Sharma, E. Krebs \& W. Kaumanns (2006). Reproductive biology of Lion-tailed Macaque (Macaca silenus):an important key to the conservation of an endangered species. Current Science 90: 804-811.

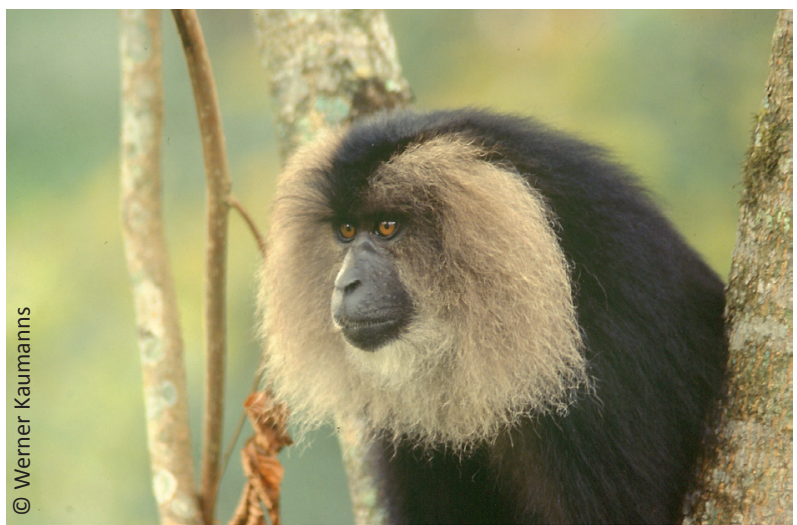

Image 2 . A young adult female in the wild

Singh, M., M. Singh, M.A. Kumar, H.N. Kumara, A.K. Sharma \& W. Kaumanns (2002). Distribution, population structure, and conservation of Lion-tailed Macaques (Macaca silenus) in the Anaimalai Hills, Western Ghats, India. American Journal of Primatolgy 57(2): 91-102; http://dx.doi.org/10.1002/ajp.10037

Singh, M., T. Jeyaraj, U. Prashanth \& W. Kaumanns (2011). Male-male relationships in Lion-tailed Macaques (Macaca silenus) and bonnet macaques (Macaca radiata). International Journal of Primatology 32: 166-176.

Singh, M. \& W. Kaumanns (2005). Behavioural studies: A necessity for wildlife management. Current Science 89: 1230-1236.

Singh, M., W. Kaumanns \& G. Umapathy (2012). Conservation-oriented captive breeding of primates in India: Is there a perspective? Current Science 103: 1399-1400.

Singh, M., W. Kaumanns, M. Singh, H.S. Sushma \& S. Molur (2009). The Lion-tailed Macaque Macaca silenus (Primates: Cercopihecidae): conservation history and status of a flagship species of the tropical rainforests of the Western Ghats, India. Journal of Threatened Taxa 1(3): 151-157; http://dx.doi.org/10.11609/JoTT.o2000.151-7

Sliwa, A. (2007). European Studbook for the Lion-tailed Macaque (Macaca silenus). Zoologischer Garten Köln, Cologne, 89pp.

Sliwa, A. (2011). European Studbook for the Lion-tailed Macaque (Macaca silenus). Zoologischer Garten Köln, Cologne.

Snyder, N.F.R., R. S.R. Derrickson, S.R. Beissinger, J.W. Wiley, T.B. Smith, W.D. Toone \& B. Miller (1996). Limitations of captive breeding in endangered species recovery. Conservation Biology 10(2): 338-348; http://dx.doi.org/10.1046/j.1523-1739.1996.10020338.x

Umapathy, G., S. Hussain \& S. Shivaji (2011). Impact of habitat fragmentation on the demography of Lion-tailed Macaque (Macaca silenus) population in rainforests of Anamalai Hills, Western Ghats, India. International Journal of Primatology 32(4): 889-900; http:// dx.doi.org /10.1007/s10764-011-9508-9

Walters, C. (1997). Adaptive policy design: thinking at large spatial scales, pp. 386-394. In: Bissonette (ed.) Wildlife and Landscape Ecology. Springer-Verlag, New York.

Walter, C. \& R. Hilborn (1978). Ecological optimization and adaptive management. Annual Review of Ecology and Systematics 9: 157-188.

Westergaard, G.C. (1988). Lion-tailed Macaques (Macaca silenus) manufacture and use tools. Journal of Comparative Psychology 102(2): 152-159; http://dx.doi.org/10.1037/0735-7036.102.2.152

Zinner, D., J. Hindahl \& W. Kaumanns (2001). Experimental group encounters in Lion-tailed Macaques (Macaca silenus). Primate Report 59: 77-92.

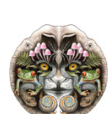

